\title{
Deformation parameters of soils determined by the cone penetration test
}

\author{
Roman Bulko ${ }^{1 *}$, Filip Gago ${ }^{2}$ \\ ${ }^{1}$ University of Žilina, Faculty of Civil Engineering, Department of Geotechnics, Univerzitná \\ 8215/1, 010 26, Slovakia \\ ${ }^{2}$ University of Žilina, Faculty of Civil Engineering, Department of Geotechnics, Univerzitná \\ 8215/1, 010 26, Slovakia
}

\begin{abstract}
The article deals with the derivation of correlation relations from the cone penetration test, which are applied as input parameters in the calculations of advanced constitutive soil models. Numerical modelling has become important part of geotechnical calculation. Hand in hand there is a big demand for accurately determined input parameters for constitutional models, that are not usually determined by IG surveys. On the model area we applied fieldworks as cone penetration tests and boreholes to obtain detailed parameters. Soil samples were examined in laboratory to create own database of values. Derived correlations include compression index $C_{c}$ and recompression index $C_{r}$.
\end{abstract}

\section{The principle of a cone penetration test}

The cone penetration test (Fig.1) is one of the geotechnical field methods used to determine the geotechnical properties of soils. The measuring cone is statically pushed through a set of steel rods into the soil by a constant speed of $20 \mathrm{~mm} \cdot \mathrm{s}^{-1}$. During penetration, number of variables are recorded at the cone head or along the sleeve. Values as cone resistance $q_{c}$, friction on sleeve $f_{s}$ and pore pressure $u_{1} / u_{2}$ are continuously recorded. At the cone the cone resistance is recorded, which expresses the resistance of the soil to penetration. The total resistance of the penetrated system $q_{t}$ is then summation of the cone resistance $q_{c}$ and the friction on sleeve $f_{s}$. Changing the penetration probe from the mechanical tip to the piezocone, enables to measure the pore pressures $u_{l}$ (measurement at the cone) or $u_{2}$ (measurement just behind the cone).

\footnotetext{
* Corresponding author: roman.bulko@fstav.uniza.sk
} 


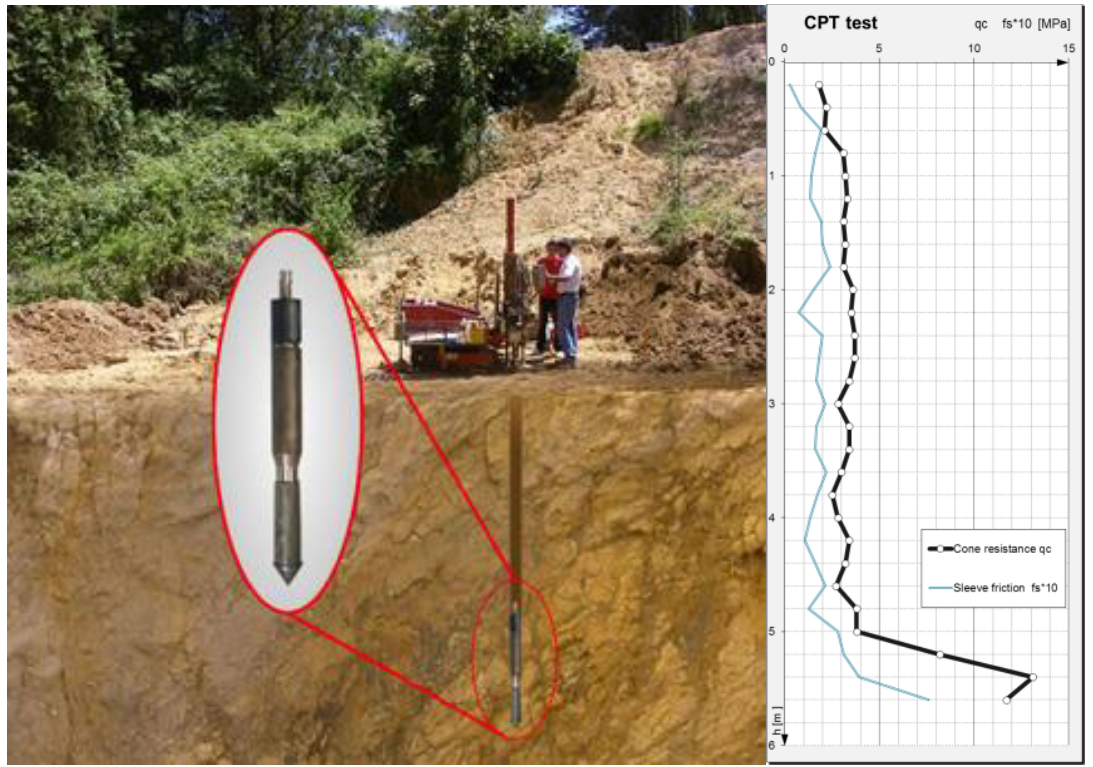

Fig. 1 Demonstration of cone penetration test

Cone Penetration Tests are divided according to used type of the measuring cone on:

- $C P T m$ - Cone Penetration Test with mechanical Begemann cone,

- $C P T u$ - Cone Penetration Test with piezocone,

- SCPTu-Seismic Cone Penetration Test.

\section{The fieldwork on the model area}

Various programs using finite element methods have been used as Plaxis, Midas, Adina and others to analyse some geotechnical tasks. Constitutional models of soils and their input parameters are base data to be entered into the different programs. In our research we have focused on the development of new correlations for the input parameters of advanced constitutional models derived from the cone penetration test.

Input data for derivation of correlation were obtained by Engineering Geological (EG) survey on model area (Fig.2). The EG survey was performed by six core boreholes $5 \mathrm{~m}$ long. Four cone penetration probes $(C P T m)$ each of the length of $5.6 \mathrm{~m}$ were allocated to each core borehole. Representative soil samples were taken from the core boreholes from the depths of $1.0 \mathrm{~m}$ to $5.0 \mathrm{~m}$ at intervals of $0.2 \mathrm{~m}$. Soil samples were tested in the Geotechnical Laboratory of the University of Žilina. Laboratory tests were done as follows:

- Granulometric analysis, humidity test, evaluation of plasticity and fluid limits;

- Shear box test;

- Determining the apparent density of solid particles;

- Oedometric test. 


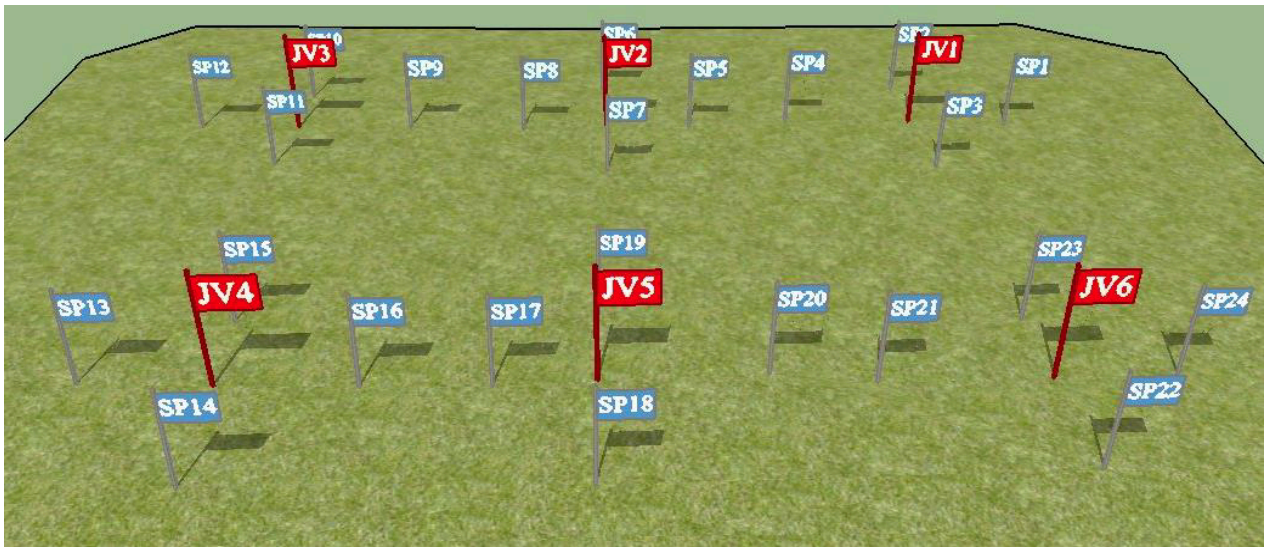

Fig. 2 Deployment of CPT probes and core boreholes on model area

The soils were classified in the graph (Fig.3) depending on the normalized penetration resistance $q_{C N}(1)$ and the friction ratio $F_{r}(2)$ based on the continual recording of cone penetration tests. This classification was introduced by Robertson, who described each area of the graph.

$$
q_{C N}=q_{c} \cdot C_{q} \quad \text { ak } \quad C_{q}=\frac{1.7}{\left(\frac{\sigma_{v}}{p_{a}}+0.7\right)}
$$

where:

$$
\begin{array}{ll}
q_{c}-\text { cone resistance } & {[\mathrm{MPa}],} \\
p_{a}-\text { reference stress } & {[0.1 \mathrm{MPa}],} \\
\sigma_{v}-\text { geostatic vertical stress } & {[\mathrm{MPa}],} \\
C_{q}-\text { stress normalization factor } & {[\mathrm{MPa}] .}
\end{array}
$$

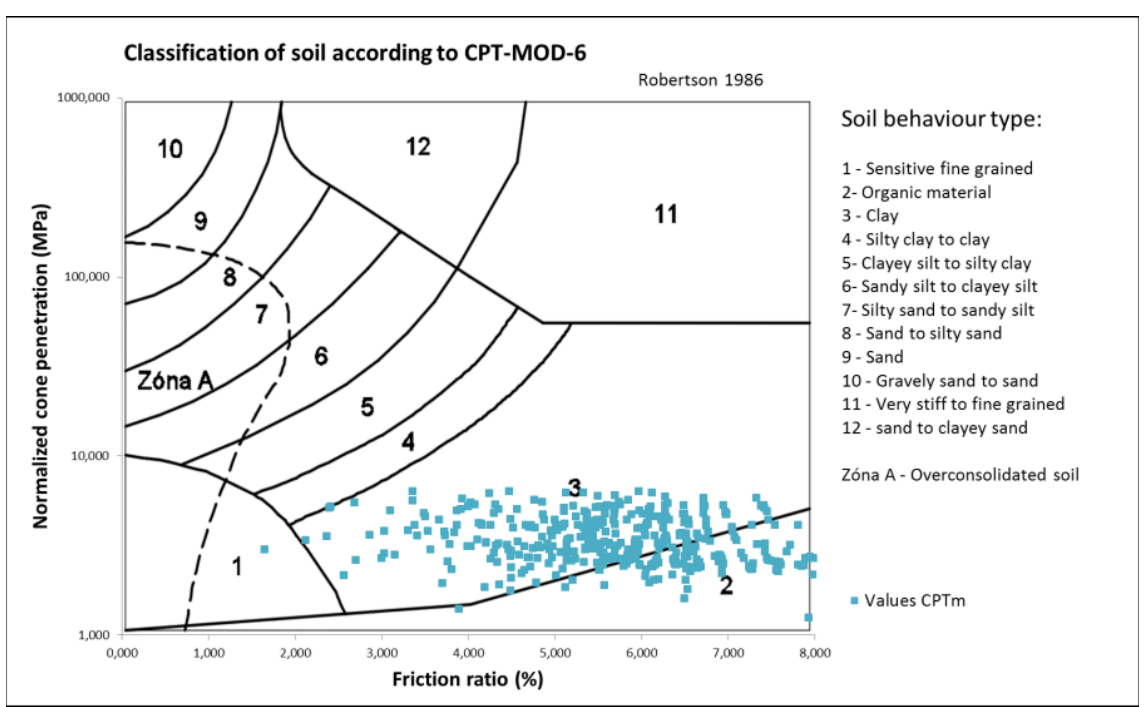

Fig. 3 Clasification of soils from model area 


$$
F_{r}=\frac{100 \cdot f_{S}}{q_{c}-\sigma_{v}}
$$

where:

$$
\begin{array}{ll}
f_{s}-\text { sleeve friction } & {[\mathrm{MPa}],} \\
q_{c}-\text { cone resistance } & {[\mathrm{MPa}],} \\
\sigma_{v}-\text { geostatic vertical stress } & {[\mathrm{MPa}]}
\end{array}
$$

\section{Constitutive models}

As it has been already mentioned, various FEM programs are used to analyse complex geotechnical tasks. The more complex the geotechnical tasks are, the better understanding of the situation is required. This is the case of more advanced constitutive soil models. An important question in numerical modelling in geotechnics is therefore the question, how to use the constitutive model for proper calculations and how to determine model input parameters. Another question is the degree of precision of the description of soil behaviour using individual models versus widely known facts.

Soil models - also called constitutional models - can be divided into two basic groups, linear and nonlinear. Linear models give a fairly fast, but none too accurate estimation of actual soil behaviour. They can be used in cases where we are only interested in stress or deformation of the massif. They are not well applicable for the method of plane of possible failure. However, if we try to do a credible description of the behaviour of the earth construction, or when we are interested in the distribution of possible areas of failure, it is necessary to use non-linear models. We chose an advanced Soft soil model for our work.

One of the input parameters is the modified compression index $\lambda^{*}(3)$. This parameter is obtained from a triaxial test and entered into the Soft soil model. If the modified compressibility index $\lambda^{*}$ is not known from a triaxial test, it can be roughly determined from the compression index $C_{c}$, determined by the oedometric test:

$$
\lambda^{*}=\frac{C_{c}}{2,3 \cdot(1+e)}
$$

where:

$$
\begin{aligned}
& C_{c}-\text { compression index, } \\
& e-\text { void ratio. }
\end{aligned}
$$

Another input parameter is the modified swelling index $\kappa^{*}(4)$. This parameter is entered into the Soft soil model and retrieved again from the triaxial test. If the modified swelling index $\kappa^{*}$ is not known from the triaxial measurement, it can be approximated by the $C_{r}$ recompression index, which is determined by the oedometric test:

$$
\kappa^{*}=\frac{C_{r}}{2,3 \cdot(1+e)}
$$

where:

$$
C_{r} \text { - recompression index. }
$$

If results from laboratory tests or in-situ tests are not available, we can use the following relationship to determine the $C_{r}$ recompression index:

$$
C_{r}=\frac{1}{5} \sim \frac{1}{10} C_{c}
$$




\section{New correlations depending on cone penetration test}

Thirty one oedometric tests were carried out in the geotechnical laboratory, with a load of 50-100-150-200-150-100-50-100-150-200 $\mathrm{kPa}$. Such load patterns also provided a branch of unloading and re-strain, from which it was later possible to determine the compression index $C_{c}$ and the recompression index $C_{r}$.

The compression index $C_{c}$ was obtained from the oedometric test, which describes the dependence of the porosity change $e$ on the change of the effective stress $\sigma_{e f}$ plotted in the logarithmic scale. It is therefore the deformation characteristic of the overconsolidated soil, which is given by the relation (6):

$$
C_{c}=\frac{\Delta e}{\Delta \log \sigma_{e f}}
$$

where:

$\Delta e$ - void ratio,

$\Delta \log \sigma_{e f}-\log$ arithmic effective stress.

Compression index $C_{r}$

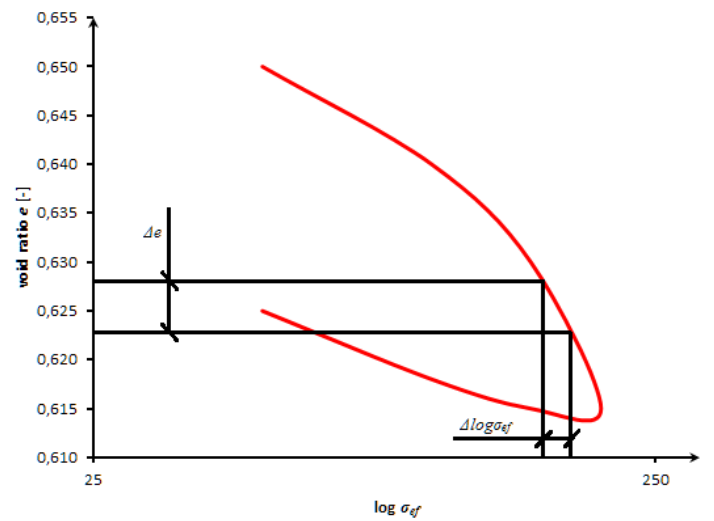

Fig. 4 The oedometric test and the dependance of the change of the void ratio on the change of the effective stress

The recompression index $C_{r}$ is obtained from the oedometric test, the unloading/reloading curve and the dependence of the porosity change $e$ on the change in the effective stress $\sigma_{e f}$ plotted on the logarithmic scale. It is a deformation characteristic of overconsolidated soil. The determination of the recompression index $C_{r}$ is given by the relation (7):

$$
C_{r}=\frac{\Delta e}{\Delta \log \sigma_{e f}}
$$

where:

$\Delta e$ - changing void ratio for curve unloaded - reloaded,

$\Delta \log \sigma_{e f}-$ changing effective stress for curve unloaded - reloaded. 
Recompression index $C_{r}$

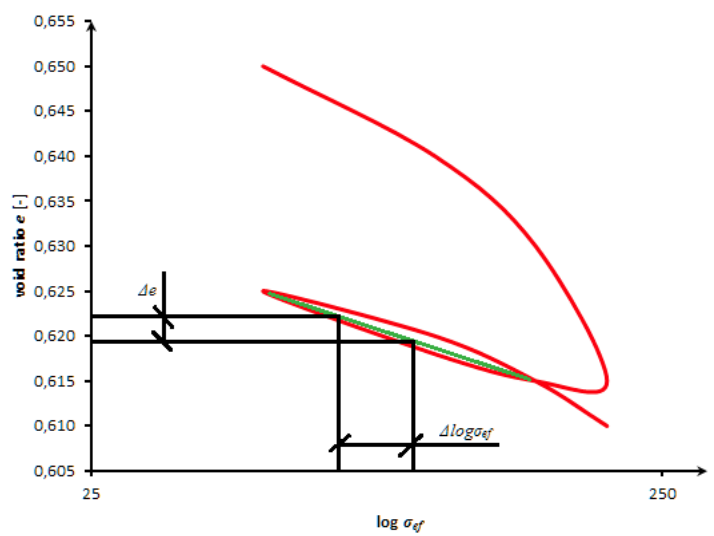

Fig. 5 The oedometric test and the dependance of the change of void ratio on the change of the effective stress for curve unloaded - reloaded

On the base of the tests, having a sufficiently large database of values of compression index $C_{c}$ and the $C_{r}$ recompression index, we deduced the dependence between these values and the measured values of the normalized penetration resistance $q_{C N}$. The correlation relation refers to the medium plasticity clays F6 (CI) classified according to STN 73 1001. On the figure (Fig. 8) we can see the distribution of 31 measured values of the compression index. We have to point out that the measured compression index values ranged from 0.07 to 0.24 . The compression index $C_{c}$ is given by the relation (8):

$$
C_{c}=0.0077 . q_{C N}^{3}-0.0776 . q_{C N}^{2}+0.2591 . q_{C N}-0.1863
$$

Based on the determination of the standard deviation, no extreme values were found. To $100 \%$ of the results, we can derive the compression index $C_{c}$ with $77 \%$ accuracy based on the relationship (8)



Fig. 6 Compression index $\mathrm{C}_{\mathrm{c}}$ derived from normalized penetration resistance $\mathrm{q}_{\mathrm{CN}}$ 
Recompression index $C_{r}(9)$ is derived from normalized cone resistance and is given by the relation:

$$
C_{r}=0.0008 . q_{C N}{ }^{3}-0.01 . q_{C N}{ }^{2}+0.0425 \cdot q_{C N}-0.0385
$$

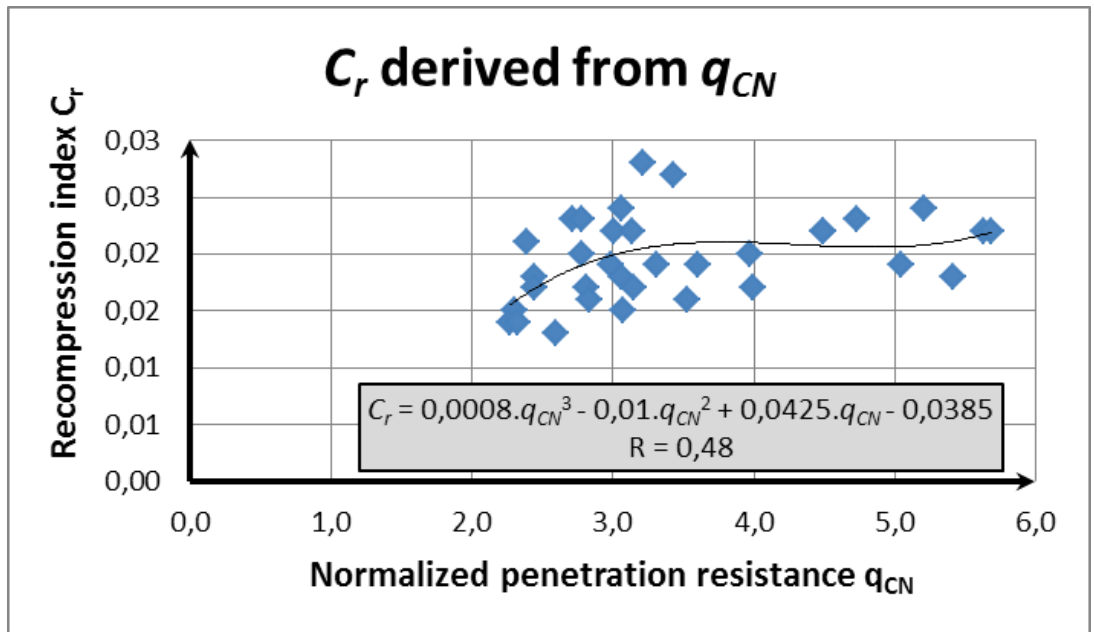

Fig. 7 Recompression index $C_{r}$ derived normalized penetration resistance $q_{C N}$

\section{Conclusion}

The ability to determine the advanced geotechnical parameters from Cone Penetration Tests is an indisputable asset. It is promising and providing possibilities for their extended usage. New correlations need to be verified in practice and, of course, they need to be refined or improved by feedback. In the future, the authors plan to deal with the correlation of the presented parameters in relation to the assessment of geotechnical structures, or for their direct usage for numerical analyses. From the engineering and geological point of view, it is evident that the knowledge of the local properties of fine-grained soils obtained by penetration probing is unique. But their extend usage should be examined for certain conditions. They can be used for similar problems to contribute to the discovery of hazards and pitfalls in the rock environment, as potential liquefaction during seismic shaking, overconsolidation, etc.

\section{References}

1 M. Decký, M. Drusa, Navrhovanie a kontrola kvality zemných konštrukcií inžinierskych stavieb. Krupa Print ISBN 978-80-970139-1-2.

2 M. Drusa, Proceedings of SGEM, 2, 151-158 (2012)

3 P. W. Mayne, Cone Penetration Testing State of Practice, Final Report NCHRP Project 20-05, Transportation Research Board, Washington (2007)

4 Research project VEGA No. 1/4215/07 Evaluation of penetrating methods for determining the deformation properties of subsoil of transport constructions and their verification in geotechnical practice (2009)

5 P. K. Robertson, Canadian Geotechnical Journal, 27/1, 151-158 (1990)

6 J. Vlček, R. Bulko, WMESS world multidisciplinary earth sciences symposium CDROM, s. 104 (2015) 
7 R. Bulko, L. Kais, J. Vlček,: Použitie statickej penetračnej skúšky pre určovanie geotechnických parametrov. Nové poznatky v geotechnickom inžinierstve - Bratislava (2014)

8 R. Bulko, Drusa, J. Vlček, M. Mečár, Civil and environmental 11/2, 152-157 (2015)

9 STN 721001 : 2010 : Klasifikácia zemín a skalných hornín.

10 STN 721027 : 1983 : Laboratorní stanovení stlačitel'nosti zemin v edometru 